\title{
Corrigendum
}

\section{Influence of Cocaine History on the Behavioral Effects of Dopamine D3 Receptor-Selective Compounds in Monkeys}

BL Blaylock, RW Gould, A Banala, P Grundt, RR Luedtke, AH Newman and MA Nader

Neuropsychopharmacology (2012) 37, 2550; doi:10.1038/npp.2012.98

Correction to: Neuropsychopharmacology (2011) 36, 1104-1113; doi:10.1038/npp.2010.248; published online 2 February 2011
In this article, there is an error in Figure 3. A revised Figure 3 is shown below.
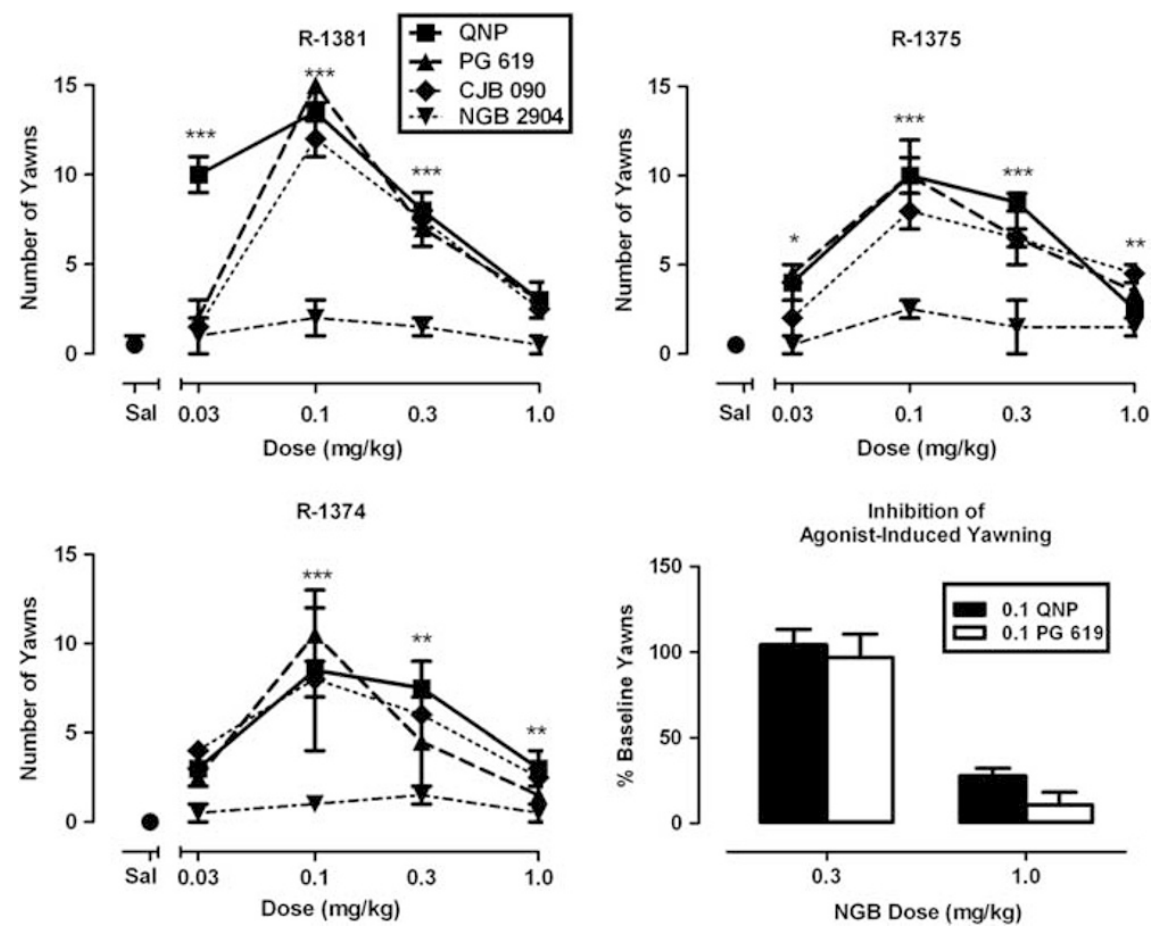

Figure 3 